\title{
Determination model of optimal operating length for modern tram
}

\author{
Y.H. LI \& K.M. CHEN \&Y. LI \& Y.Q. CHENG \\ School of Highway, Chang'an University, Xi'an, Shaanxi, China
}

KEYWORD: Modern tram, Net-operation separation, Optimal operating length

ABSTRACT: With consideration of operating speed, road conditions, economic benefits, and forecast passenger volume, an optimization method was proposed to determine the optimal length of modern tram line. Based on the principles of net-operation separation, theoptimal operating length of tram is determined according to tram road characteristics, and the model was verified by an example. Analysis result showed that the optimal length for modern tram lines are between $15 \mathrm{~km}$ and $25 \mathrm{~km}$ under normal intensities of passenger flow, which was inversely proportional to the optimal length of tram line.

\section{INTRODUCTION}

Modern tram is functional similar to Bus Rapid Transit(BRT) (CJJ/T 114-2007). They are belong to middle-low transit modes between regular transit and subway. Tram mainly laid on the city road surface, and operating mixed with other vehicle transportation. Compared with BRT, the tram system is more complex, higher cost, and the tram train is constitute of 2-7 modules(Lu Ximing et al. 2013). With the development of urbanization, the tram have a further improvement for traffic volume. So the tram has very broad applicability, include:1. Supplementary of metropolitan where lack of railway transit; providing density and connection capabilities;2. Distribution of external groups inside big cities;3. Main transit system in medium and small cities;4. For special purposes, such as tourism line(Zhang Zidong. 2013).The ordinary modern tram is shown as Figure 1.

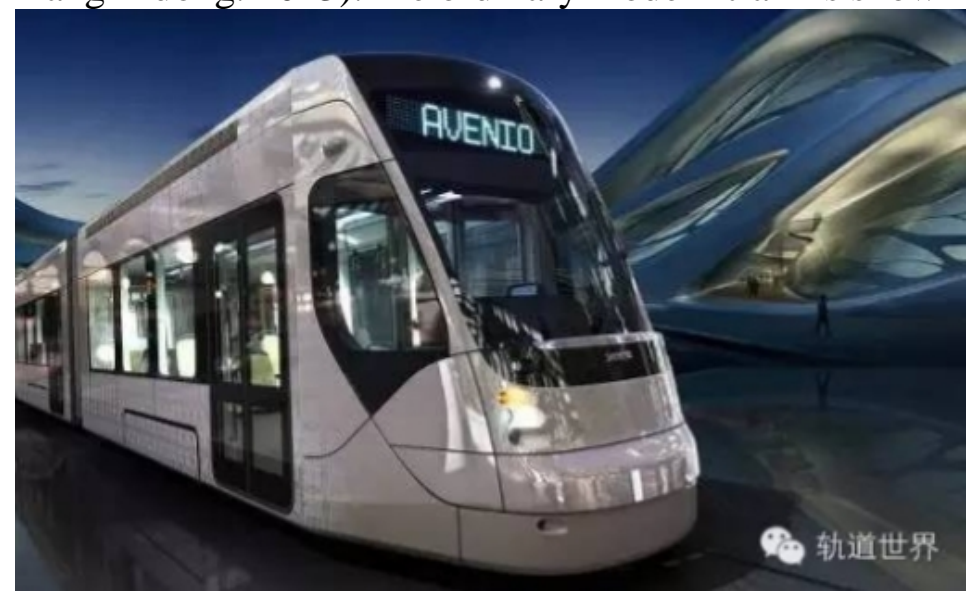

Figure 1. The ordinary tram

The main difference of tram and urban rail transit is that the tram is separated in net and operation. Different operation lines can be determined on different passenger demand, different road environment, different urban development level in one tram network. These characteristics above determine the need to confirm the optimal operating lengths,make sure the rationality of operational management, economic, supply and demand, which provide useful references for future planning, design, and operation(Zhang Zidong et al. 2013).

Chen(2009) studied the relationship between passenger distributing centers and urban rail transit network,put forward a new method to calculate urban rail transit network scale based on the connectivity between passenger distributing centers(CHEN Kuan-min et al. 2009). Luo(2010) discussed the optimal method of urban rail transit line length from the economic point of view, and the relationship between length and construction costs, vehicle purchasing costs, operating and maintenance costs, the saving value of travel time and the ticket income of urban rail transit (LUO Xiao-qiang et al. 2009). Wang(2011) researched the reasonable economic length of the regional rail transit line 
from economic point of view(WANG Shao-nan et al. 2011). Gong(2012) considered the influence of speed, efficiency and benefits of urban rail transit lines, interval of stations and passenger traffic density on urban rail transit lines length,established a model with the maximum value of the relative net benefits(Gong Qian et al. 2012) .

For the moment, many cities have planned and constructed the modern tram.Generally speaking, the problem of optimal length of urban tail transit is still in the research, and optimal operating length for modern tram has not yet been studied. In order to meet the diversities of domestic rail transportation, and provide properly suggestions for tram planning, it's urgently need to quantify the analytical techniques to guide the tram route planning, design and operating length.

\section{FEATURES OF MODERN TRAM}

1. Operating on the road, the technical parameters are between bus and subway. 2. Peak hour traffic volume could reach $5000-10000$ passengers. 3. Maximum speed is $70 \mathrm{~km} / \mathrm{h}$, the average operating speed is $15-25 \mathrm{~km} / \mathrm{h}$ in urban area , and $30 \mathrm{~km} / \mathrm{h}$ in suburban area(Lu Ximing et al. 2013) . 4. Smaller radius curve is permissible in tram planning, adaptive to tough road conditions . 5. Separated in operating network and line network . 6. Tram is flexible in module so it can adapt to the future elastic development of new city .7. Tram can be designed as tangent line outside the big city, backbone of small city, connections for areas surround the end of subway line . 8. Influenced by operating speed, boundary conditions, road conditions, the operating length can not be very long . 9. Consider the signal priority at intersections in order to promote the operating efficiency(SHEN Jing-yan. 2008).

\section{FACTORS OF TRAM OPERATING LENGTH}

For railway, the main factors influence the route planning are natural conditions, the geological conditions, power supply, ventilation, signal, depot, environment, heritage conservation, construction cost, financial. In the process of tram planning, we should consider the following questions : Urban agglomeration planning, Urban planning, Network planning, land properties, industry and professions, transportation development, population distribution , demand analysis . Compared with the general urban subway, tram has its own unique character. From the perspective of operation, the tram belong to the upgrading mode of bus. Compared with the subway and light railway, the tram operating separated with network. Its operating line is based on passengers volume, land use, important nodes, and planning different operating line in the same network . Compared with subway, tram is more vulnerable effected by road traffic, intersections and other external factors(JIN Feng. 2008) .

Because of the above characteristics of the tram, determined the research of optimal operating length for tram is more complex than subway. Thus, total construction costs, passenger flow, the time value of benefits are important considerations(Li Tai-hui. 2008).

\section{DETERMINATION MODEL OF OPTIMAL OPERATING LENGTH}

\section{Transit volume intensity}

Transit volume intensity of subway is an important index for rail traffic operational efficiency. On the one hand, modern tram play an important role in the public transit systems, the tram line should be designed in the main traffic corridors, and connecting important passenger distribution point, major transport hub, the city's main residential and commercial group ,then provide good services for commuter passenger ; On the other hand, volume intensity also reflects the basic relationship between supply and demand of tram system, and it reflects the operational efficiency directly (Chen Kuanmin et al. 2011) . 


\section{Operating speed}

The modern tram operation is affected by road conditions significantly, the most important factor is intersection signal control and traffic management. The relationship between tram operating speed $v_{R}$ and intersection signal control modes is showed in Table 1.

Table 1. Characteristics and applicability of different signal control modes

\begin{tabular}{|c|c|c|c|}
\hline Item & $\begin{array}{l}\text { Complete } \\
\text { signal } \\
\text { priority }\end{array}$ & $\begin{array}{c}\text { Part signal } \\
\text { priority }\end{array}$ & $\begin{array}{l}\text { No signal } \\
\text { priority }\end{array}$ \\
\hline $\begin{array}{l}\text { Influence } \\
\text { on the } \\
\text { transverse } \\
\text { vehicles }\end{array}$ & $\begin{array}{c}\text { Greater de- } \\
\text { lay }\end{array}$ & Some delay & $\begin{array}{c}\text { No specific } \\
\text { delay }\end{array}$ \\
\hline $\begin{array}{l}\text { The aver- } \\
\text { age travel } \\
\text { speed }(\mathrm{km} \\
\quad / \mathrm{h})\end{array}$ & $20-30$ & $17-25$ & $15-20$ \\
\hline $\begin{array}{c}\text { Realization } \\
\text { Difficulty }\end{array}$ & $\begin{array}{l}\text { Very com- } \\
\text { plicated }\end{array}$ & Complicated & Easy \\
\hline $\begin{array}{l}\text { Scope of } \\
\text { application }\end{array}$ & $\begin{array}{l}\text { Transverse } \\
\text { road with } \\
\text { low traffic } \\
\text { volume and } \\
\text { lower road } \\
\text { grade in in- } \\
\text { tersection }\end{array}$ & $\begin{array}{c}\text { Tram line } \\
\text { intersect } \\
\text { with trunk } \\
\text { road and } \\
\text { most of sec- } \\
\text { ondary } \\
\text { road ,most } \\
\text { of branch } \\
\text { road }\end{array}$ & $\begin{array}{l}\text { Intersection } \\
\text { of line and } \\
\text { trunk road, } \\
\text { transverse } \\
\text { road is } \\
\text { close to sa- } \\
\text { turation, } \\
\text { mixing } \\
\text { road rights }\end{array}$ \\
\hline
\end{tabular}

As tram is operating on road, and belong to open rail system. The entrance on both sides of street, entrance of commercial facilities would affect the operating speed of tram . The tram located on different road lane has different speed reduction which can be determined by Table 2(Chen Kuanmin et al. 2011).

Table 2. Characteristics and applicability of different signal control modes

\begin{tabular}{ccc}
\hline $\begin{array}{c}\text { Layout form of } \\
\text { tram }\end{array}$ & $\begin{array}{c}\text { middle in the } \\
\text { road }\end{array}$ & $\begin{array}{c}\text { sides of the } \\
\text { road }\end{array}$ \\
\hline $\begin{array}{c}\text { Operating } \\
\text { speed reduction }\end{array}$ & 1.0 & 0.5 \\
\hline
\end{tabular}

\section{Operating speed}

Railway station parking time mainly determined by passengers amount of on and off, especially the time of passengers to get on and off . Tram parking time could be calculated as followed equation :

$$
t_{P}=\frac{\left(P_{\text {ON }}+P_{\text {OFF }}\right) t_{\text {ON/OFF }}}{n m d}
$$

Where $P_{O N}, P_{O F F}=$ The on and off volume of passengers in respective stations, determined by passengers flow forecast $. t_{O N / O F F}=$ The average time required for each passenger getting on or off (unit: seconds). Based on investigation, taking 0.6s $. n=$ Number of operating tram per hour $. m=$ Number of train marshalling. Tram marshalling number based on the passenger demand forecasts , usually take 2-7 module $. d=$ Number of each module unilateral doors, under normal circumstances, each module unilateral door is 2 . 


\section{Construction costs}

Tram is belonging to low-middle volume mode in transit system, so the construction costs is higher than the cost of general bus and BRT . The average cost of tram lines (including construction, installation costs and vehicle purchase costs) is 80-90 million yuan / km, which the vehicle purchase costs accounted for 30\% -35\% , and cost about 25-30 million yuan / column. Compared with the same passengers capacity like BRT, the tram is undoubtedly an expensive investment. The overall cost of tram can be calculated as follows:

$$
C=c^{\prime} L
$$

Where $C=$ the total construction costs of the tram line; $c^{\prime}$ is construction costs per unit length; $L$ is the length of the tram line.

\section{Operation and maintenance costs}

The operation and maintenance costs of urban railway is higher in the operating period . Considering the maintenance costs of tram-depot and other ancillary facilities have less relationship with length, so they will not be considered. Therefore, the costs of operation and maintenance are consist of tram lines and stations. In general, the unit length operation and maintenance costs can be regarded as proportional to passengers volume was, and station maintenance costs was proportional to the number of stations. After comprehensive analysis ,the tram operation and maintenance costs are similar with subway maintenance costs, and can be determined with the following formula:

$$
\Phi_{i}=c_{i} L
$$

Where $c_{i}=$ the $\mathrm{i}(\mathrm{th})$ year average maintenance costs per unit length,the value is $\quad(0.90-1.23)$ $\times 10^{7}$ yuan $/ \mathrm{km}$ 。

\section{Saving value of travel time}

The saving value of travel time can be regarded as the difference between tram average travel time and bus. The relative average travel saving time is :

$$
\bar{t}_{i}=\bar{t}_{B i}-\bar{t}_{R i}
$$

Where $\bar{t}_{R i}=$ is the average travel time of tram in the $\mathrm{i}$-th year (hour/one unit passenger).

The average travel time including three parts, among these are travel time, tram parking time , walking time of the start and the end of tram line, which can be calculated as follows:

$$
\bar{t}_{R i}=\frac{\bar{l}_{R i}-2 D_{R}}{v_{R}}+t_{S}+\frac{2 D_{R}}{v_{w}}
$$

Where $\bar{l}_{R i}=$ the average transport distance in the $\mathrm{i}$-th year, which can be determined by passenger flow forecast; $v_{R}=$ the average operating speed of tram; $D_{R}=$ the walking distance from tram station to trip destination, based on the average public transit service radius , and the value is $0.5 \mathrm{~km} ; t_{S}=$ tram parking time ; $v_{w}=$ average walking speed, taking $3.5 \mathrm{~km} / \mathrm{h}$.

$\bar{t}_{B i}$ is the average travel time of bus in the i-th year (hour/one unit passenger), can be calculated according to the following formula:

$$
\bar{t}_{B i}=\frac{\bar{l}_{R i}-2 D_{B}}{v_{B}}+\frac{2 D_{B}}{v_{w}}
$$

Where $D_{B}=$ distance from arrival place to bus station, taking $0.5 \mathrm{~km} ; v_{B}=$ average operating speed of bus, according to the actual transportation investigation.

\section{Ticket income}

General urban rail transit calculate ticket fare by distance, therefore, tram ticket income may also viewed as a function of the travel distance, the tram ticket income can be calculated as follows:

$$
\bar{f}_{i}=f_{0}+\Delta \bar{l}_{R i}
$$

Where $f_{0}=$ the starting fares of tram ; $\Delta f=$ the increasing fares by each travel distance unit from the starting fares (yuan/km). 


\section{Optimal model}

From the above discussions, the optimal operating length model could be considered as the situation of net benefit maximum. Tram relatively net income could estimated from invested and benefits . The income is mainly from tram ticket income and passenger relative saving time value. The benefits is mainly from tram construction and operation of investment. Taking consideration of investment for the one-time construction of the tram, whereas tram tickets and the saving time value of income will be exist ever since. Therefore, when calculating the maximum net benefit ,it's based on passengers volume forecast and overall network plan, take consideration of both investment and benefits, discounted to the base year. The maximum value can be expressed as the following formula:

$$
\max Z=\sum_{i=1}^{n} \frac{Q_{R i}\left(\eta \bar{t}_{i}+\bar{f}_{i}\right)-\Phi_{i}}{(1+\gamma)^{i}}+\frac{C}{365}
$$

Where $Q_{R i}=$ the daily average passengers volume of tram in the i-th year ; $Q_{R i}=\alpha L, \alpha=$ the passengers volume intensity of the network , $L=$ tram operating length ; $\eta=$ the time value per unit ; $\gamma=$ the discount rate; The meanings of other symbols are showed above .

In summary, the optimal model can be summarized as follows:

$$
\begin{gathered}
\max Z=\sum_{i=1}^{n} \frac{Q_{R i}\left(\eta \bar{t}_{i}+\bar{f}_{i}\right)-\Phi_{i}}{(1+\gamma)^{i}}+\frac{C}{365} \\
\text { s.t. }\left\{\begin{array}{c}
\overline{t_{i}}=\bar{t}_{B i}-\bar{t}_{R i} \\
t_{P}=\frac{\left(P_{O N}+P_{O F F}\right) t_{\text {ON/OFF }}}{n m d} \\
\bar{t}_{B i}=\frac{\bar{l}_{R i}-2 D_{B}}{v_{B}}+\frac{2 D_{B}}{v_{w}} \\
\Phi_{i}=c_{i} L \\
C=c^{\prime} L
\end{array}\right.
\end{gathered}
$$

Analysis from the above model, the optimal length of the tram can be converted to unconstrained programming problems in the case of the relevant parameters determined and then solving by ultimate values.

\section{Model Solution}

This model is belong to the optimal model, and it could be solved by genetic algorithm (GA) . GA is a simulation of natural biological evolution process of self-organization and adaptive artificial intelligence technology. It's based on the natural selection and genetic theory, the process combined the biological evolution which the fittest ones survive and of random information exchange mechanisms within the group of chromosomes. Before the search, encoding the variables in some form (variable coded called chromosomes), different chromosomes constitute a group. A new generation of groups is based on the following two steps: first, according to the fitness value of the chromosome then select the appropriate number of copies to be retained; Secondly, process the selected chromosome with recombination, mutation to generate new chromosomes.

The basic algorithm process is as follows(Zheng Liping et al. 2003):

1. Selects $\mathrm{N}$ initial points randomly (described as a group, each point is called an individual), $X_{k}^{1}, X_{k}^{2}, \mathrm{~L}, X_{k}^{n}, k=0$.

2. Calculate for each individual's fitness, $f\left(X_{k}^{i}\right), i=1,2, \mathrm{~L}, N$.

3. Selection : Select $X_{k}^{\prime 1}, X_{k}^{\prime 2}, \mathrm{~L}, X_{k}^{\prime n}$ from $X_{k}^{1}, X_{k}^{2}, \mathrm{~L}, X_{k}^{n}$, and every $X_{k}^{j}(j=1,2, \mathrm{~L}, N)$ probability of being selected is

$$
P\left(X_{k}^{i}=X_{k}^{j} \mid X_{k}^{1}, \mathrm{~L}, X_{k}^{N}\right)=\frac{f\left(X_{k}^{j}\right)}{\sum_{l=1}^{N} f\left(X_{k}^{l}\right)} .
$$


4. Crossover : Select two individuals with the same probability from $X_{k}^{\prime 1}, X_{k}^{\prime 2}, \mathrm{~L}, X_{k}^{\prime n}$, Take these two individuals with restructuring operation of given probability $P_{c}$ to produce two new individuals . Repeating this process until a new group $X_{k}^{\prime 1}, X_{k}^{\prime 2}, \mathrm{~L}, X_{k}^{n}$ figure out .

5. Mutation: Change the value for each individual based on certain mutation rate $P_{m}$ randomly, and calculating a new generation of community.

6. Inspect the rationality of stop criteria, if the criteria meet the computational requirements and accuracy then operation is stopped, otherwise make $k+1=k$ and calculate it again .

\section{CASE ANALYSIS}

XiXian New Area is located between Xi'an and Xianyang, total planning area is 882 square kilometers, and construction planning area is 272 square kilometers. According to the overall planning , the area will be a "New functional city of Xi'an and eco-garden city". Meanwhile , XiXian New Area is planned in decentralized cluster pattern district. The main development idea is garden city and green city .

Based on the actual characteristics of XiXian New Area, the New Area should first implement bus priority principle, and promote low-carbon modes of transit to strengthen links between decentralized groups. The public transport development model in the New Area should be "establishing middle-low capacity transit system ". Tram is overlayed on the road, and the road network is blocked by the Weihe River, historical relics. Because of the district overall plan, the network system could built with higher standard, including highways, expressways, trunk roads and other road system, the red line of trunk roads in the new district is approximately $40 \mathrm{~m}$ or more, and both sides of the road have been planned with green belt. In conclusion, the construction of tram is enforceable.

The modern tram network has been planned nine lines in XiXian New Area, which contains two branch lines. The total length of network is 199 kilometers, and 150 stations, including 19 transfer stations, 15 transfer stations between rail and subway, as shown in Figure 2.

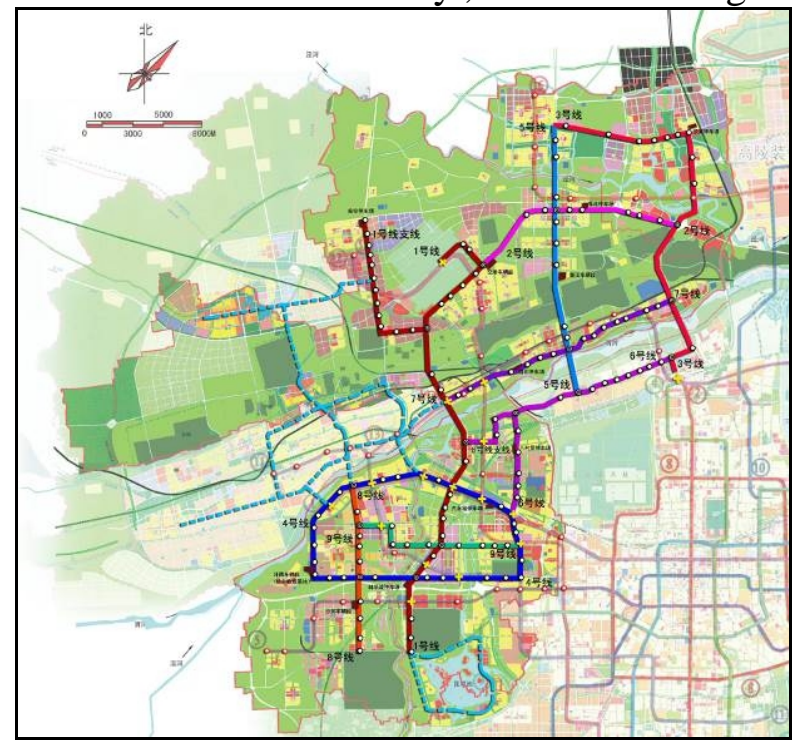

Figure 2. Modern tram network planning of XiXian New Area

The modern tram network planning, technical features, technical specifications and other aspects of project implementation as shown in Table 3. 
Table 3. Modern tram technology parameters of XiXian New Area

\begin{tabular}{cc}
\hline Items & Parameters \\
\hline Operating Speed & $20 \mathrm{~km} / \mathrm{h}$ \\
Walking distance from both & $0.5 \mathrm{~km}$ \\
ends & 90 million Yuan $/ \mathrm{km}$ \\
Construction costs & 10 Yuan / per capita \\
Üh \\
Time value & 3 Yuan \\
Ticket price & $2-5$ min \\
Departure interval & $15 \mathrm{~km} / \mathrm{h}$ \\
Operating Speed of regular \\
bus \\
Operation and maintenance \\
costs & 8 million Yuan $/ \mathrm{km}$ \\
Discount Rate & $10 \%$ \\
\hline
\end{tabular}

The traffic volume could be predicted by four-stage method, the prediction results shown in Figure 3:

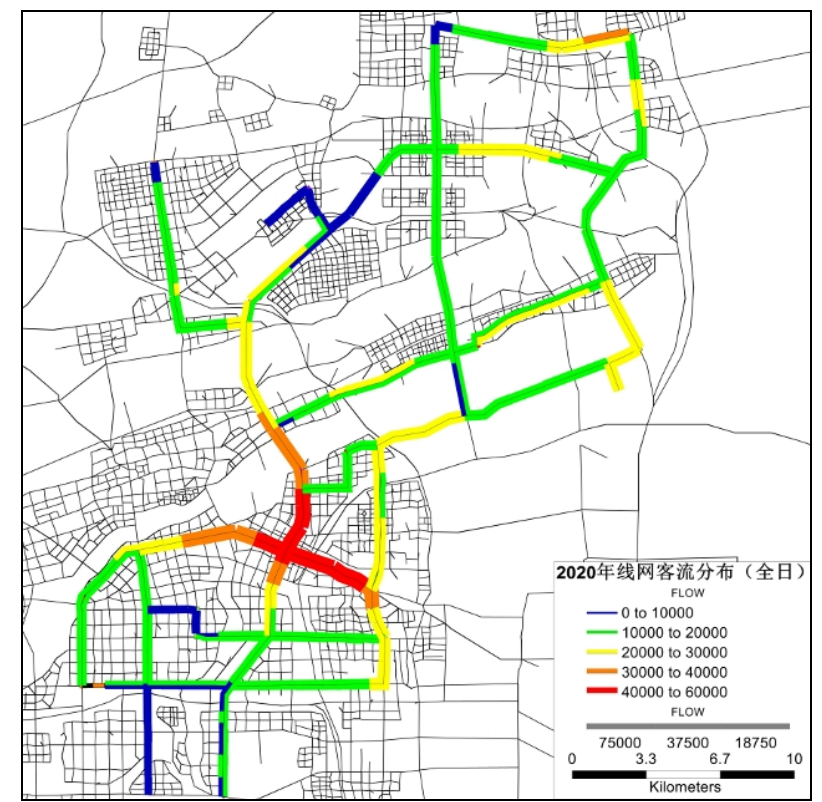

Figure 3. Modern tram traffic predictions in XiXian New Area

Based on the results of traffic volume forecast and other parameters, the optimal model could be solved by Genetic Algorithm which discussed above .

Take the parameters into the optimal model and plot the graphic of the function as shown in Figure 4. The result of iteration is shown as the Figure 5.Similarly, the tram optimal operating model can be obtained under different traffic intensity as shown in Table 4. 


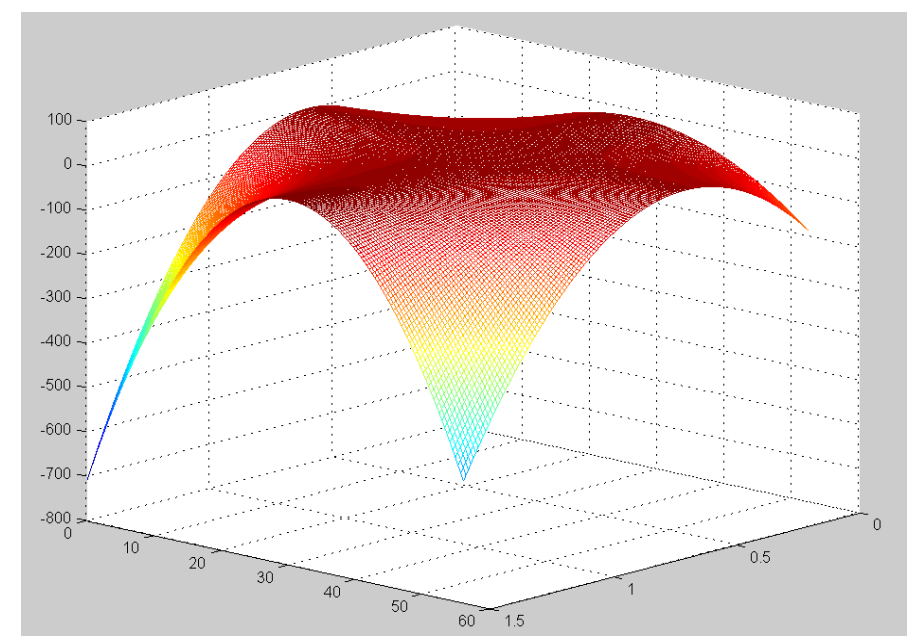

Figure 4. The figure of the optimal model

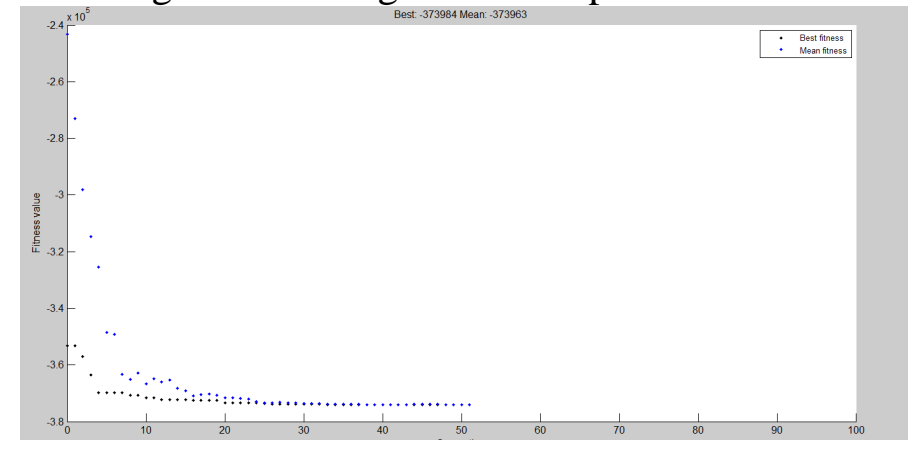

Figure 5. The result of iteration

Table 4. Calculation results of optimal model

\begin{tabular}{cc}
\hline$\alpha($ passengers $/ \mathrm{h})$ & $L(\mathrm{~km})$ \\
\hline 5000 & 36.96 \\
6000 & 30.49 \\
7000 & 25.87 \\
8000 & 22.41 \\
9000 & 19.72 \\
10000 & 17.56 \\
11000 & 15.80 \\
12000 & 14.32 \\
\hline
\end{tabular}

According to the above results, a suitable operating length of modern tram in XiXian New Area is about $20 \mathrm{~km}$. Based on the passengers volume intensity of different line, the optimal operating length is between $15-25 \mathrm{~km}$ in this area .

The tram line network planning in XiXian New Area consists of 4 lines in recent years . In consideration of optimal length simulation results, and based on the passenger volume section of network, the optimal operating lines could be planned as Figure 6 . 


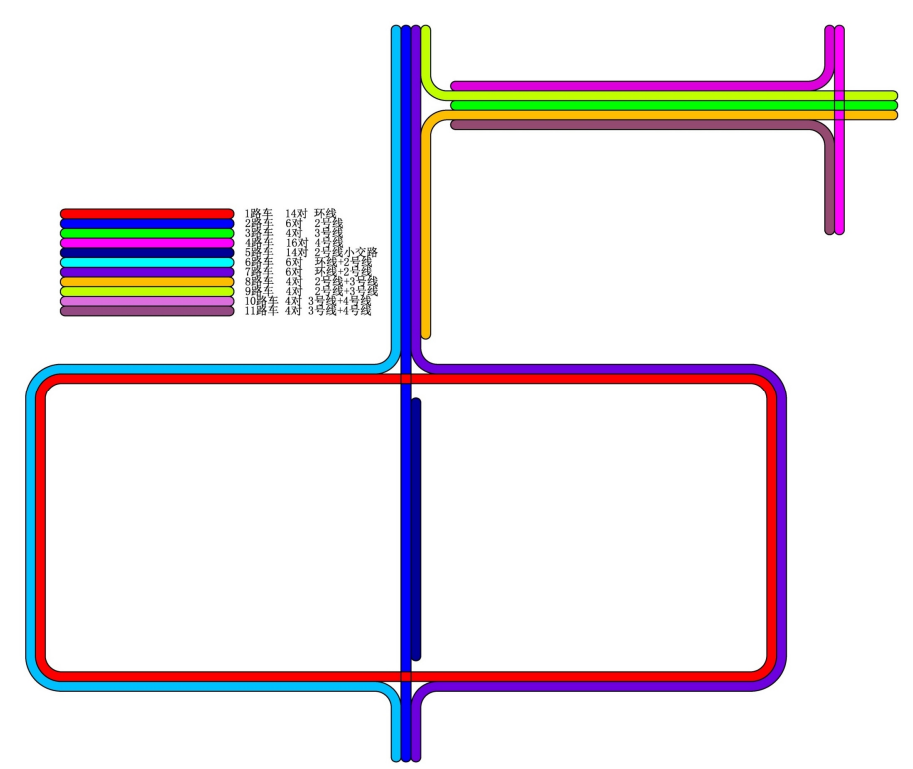

Figure 6. Modern tram operating planning of XiXian New Area

The operating length of the network are between $15-25 \mathrm{~km}$. It's in line with the requirements of tram optimal operating length, but also in line with the demand of passenger volume prediction .

\section{CONCLUSION}

1. This article is based on traffic engineering principles ,taking operating income as the objective function, combined with the factors as trams operating characteristics, operating speed, parking time, construction costs, operation and maintenance costs, saving value of travel time, ticket income, then establish the tram optimal operating length model.

2. The economic traffic volume of tram is 8000-12000 passengers /hour, based on the above model, calculated the optimal operating length of tram is $15-25 \mathrm{~km}$, the operating time is also about an hour . The optimal operating length is inversely with traffic intensity.

3. This article discussed the general factors that affect the operating length of modern tram, but in the process of actual operation and management, the operating characteristics and operating environment of the tram is more complicated than subway, so the optimal operating length should be adjusted by the urban planning, road characteristics, passenger distribution point and such actual conditions.

\section{REFERENCES}

[1] Standard for classification of urban public transportation[S] . (CJJ/T 114-2007).

[2] Lu Ximing, \& Li Na. 2013. Rational and Sustainable Development of Streetcars[J], Urban Transport of China , 11(4):19-23.

[3] Zhang Zidong. 2013. Streetcar System Planning and Design[J], Urban Transport of China, 11(4):30-38.

[4] CHEN Kuan-min, \& FAN Da-ke, \& MA Chao-qun. 2009. Cal-culation of urban rail transit network scale based on pas-senger distributing centers[J], Journal of Chang 'an Uni-versity, 29(6):78-81.

[5] LUO Xiao-qiang, \& CHEN Kuan-min. 2008. Determined mod-els of optimal length for urban rail transit line[J]. Journal of Traffic and Transportation Engineering, 10(3):64-65.

[6] WANG Shao-nan, \& LIANG Qing-huai. 2011. Research on Economic Length of Regional Rail Transit Line[J].RAILWAY TRANSPORT AND ECONOMY , 33(10):1-6.

[7] Gong Qian, \& Gu Bao-nan. 2012. Decision model of reason-able line length for urban mass transit[J].Urban Mass Transit, 011:24-28. 
[8] SHEN Jing-yan. 2008. Discussion on the length of an urban railtransit line[J].Urban Rapid Rail Transit, 21(4):5-9.

[9] JIN Feng. 2008. Reasonable length of an urban rail transit line[J].Urban Rapid Rail Transit, 21(4):1-4.

[10]Li Tai-hui. 2008. The optimal metro line length in net-work[J].Urban Rapid Rail Transit, 21(4):15-18.

[11]Chen Kuanmin, \& Yan Baojie, 2011. Highway Capacity Anal-ysis[M],Second Edition, China Communications Press, 2011.4:213.

[12]Zheng Liping, \& Hao Zhongxiao. 2003. A revised on the theory for the Genetic Algorithm[J]. Computer Engineering and Applications, 21:50-53. 